Revista Eletrônica de Direito Processual - REDP.

Rio de Janeiro. Ano 10. Volume 17. Número 2. Julho a Dezembro de 2016

Periódico Semestral da Pós-Graduação Stricto Sensu em Direito Processual da UERJ

Patrono: José Carlos Barbosa Moreira. ISSN 1982-7636. pp. 02-10

www.redp.uerj.br

\title{
A INFLUÊNCIA NORTE-AMERICANA NOS SISTEMAS PROCESSUAIS PENAIS \\ LATINOS $^{1}$
}

\section{THE AMERICAN INFLUENCE OVER THE LATIN AMERICAN CRIMINAL JUSTICE SYSTEMS}

\section{Afranio Silva Jardim}

Professor Associado de Direito Processo Penal da Uerj. Mestre

e Livre-Docente em Direito Processual. Procurador de Justiça no ERJ (aposentado).

caniljardimsilva@ caniljardimsilva.com

Preliminarmente, dedico este singelo estudo ao grande jurista José Carlos Barbosa Moreira, por tudo o que fez em prol do desenvolvimento teórico do nosso Direito Processual. Professor insuperável e autor invulgar de obras já clássicas. Devo muito a este verdadeiro mestre. Obrigado professor José Carlos Barbosa Moreira.

RESUMO: o artigo discute a influência do Direito Processual norte-americano sobre os sistemas latino-americanos, analisando a importação de alguns institutos típicos daquele modelo, tais como a delação premiada, verificando, de maneira crítica, se se estará avançando para um modelo privatista do processo penal.

PALAVRAS-CHAVE: Direito Processual Penal norte-americano; América Latina; Influência; Sistemas processuais penais; Privatização do processo.

ABSTRACT: The article talks about the American criminal justice system influence over the latin-american systems, especially about the called "privatization process", showed by some institutes, like the State's evidence.

\footnotetext{
${ }^{1}$ Artigo recebido em 01/10/2016, sob dispensa de revisão.
} 
Revista Eletrônica de Direito Processual - REDP.

Rio de Janeiro. Ano 10. Volume 17. Número 2. Julho a Dezembro de 2016

Periódico Semestral da Pós-Graduação Stricto Sensu em Direito Processual da UERJ

Patrono: José Carlos Barbosa Moreira. ISSN 1982-7636. pp. 02-10

www.redp.uerj.br

KEYWORDS: North American; criminal justice systems; privatization process; State's evidence.

\section{Temos que tomar conhecimento e refletir.}

Acabei de ler um importante livro que importei da Argentina, intitulado "Bases del nuevo código procesal penal de la nación", de autoria de Marcelo A. Solimine, ed. Had-Hoc, Buenos Aires, 2015. Esta obra cuida do sistema do código federal que ainda se encontra em "vacatio legis". Em sua parte introdutória, tal autor argentino faz uma interessante explanação sobre o movimento de reforma processual penal na América Latina. Na verdade, foram novos códigos de processo penal, em 15 países, começando pela Guatemala, em 1992 e terminando em 2009, no México.

Mais impressionante do que este tempo recorde é o fato de que todos estes novos códigos de processo penal, com estrutura do chamado sistema adversarial, sofreram influência direta de juristas e organismos dos Estados Unidos da América do Norte, conforme estudo do professor argentino Máximo Langer, escrito originalmente em inglês, já que ele estava fazendo sua pós-graduação naquele país. Escreveu Marcelo Solimini, in verbis: "A partir de alli se desencadenó un proceso de reforma que Máximo Langer muestra con detalle y profundidad, con mención de los componentes políticos e ideológicos coyunturales que le dieron impulso, incluída la injerencia de organismos de los EE.UU. e internacionales (como ILUANUD) ... que concluyó con una cascada de códigos acusatorios y reformas procesales ... (p.51/52).

Em relação ao estudo acima citado de Máximo Langer, a obra que lemos faz constar em seu rodapé n.4, pag.51: "Muestra alli la labor da la USAID (Agência de los EE.UU. para el desarrollo internacional), que patrocinó los procesos de reforma em América Latina a partir de 1985, sin imponer modelos estadounidenses y apoynando a las instituiciones locales existentes ...". Mais adiante, na p.55, Marcelo Solimine esclarece sobre a presença de grupos provenientes das universidades norte americanas nos debates sobre novos códigos de processo penal, inclusive em relação ao argentino, conforme dito por Marcos Salt, em sua exposição na Câmara de Senadores do Congresso. 
Revista Eletrônica de Direito Processual - REDP.

Rio de Janeiro. Ano 10. Volume 17. Número 2. Julho a Dezembro de 2016

Periódico Semestral da Pós-Graduação Stricto Sensu em Direito Processual da UERJ

Patrono: José Carlos Barbosa Moreira. ISSN 1982-7636. pp. 02-10

www.redp.uerj.br

Desta forma, julgo estar confirmado o que venho dizendo há muito tempo. O chamado sistema processual adversarial (sistema acusatório puro ou radical) tem origem na ideologia liberal e privatista reinante nos Estados Unidos e não atende ao interesse público.

Vários autores, que se filiam a este modelo, chegam a sustentar que o conflito decorrente do delito se dá entre aquele que pratica o crime e a vítima, motivo pelo que o Ministério Público "sequestrou" o ofendido do processo penal (sic). Assim, deve prevalecer a vontade privada destes sujeitos, mesmo que seja para afastar a incidência da lei penal (cogente, por ser pública). É a volta ao sistema romano, onde o crime era "um problema da vítima".

Neste sentido, é a tese de doutorado do argentino Francisco Castex, aprovada com a restrição que transcrevemos abaixo. $\mathrm{O}$ autor sustenta que o conflito resultante da prática do delito é, na verdade, entre o autor da infração penal e a vítima, motivo pelo que deve ser aplicada a ação penal privada e ser ampliado o poder dispositivo no processo penal, através da manifestação de vontade do ofendido. Chega-se a sugerir um sistema penal sem o Ministério Público ... A referida crítica foi feita pelo conhecido examinador professordoutor Daniel R.Pastor, in verbis:

"Sin embargo, no me imagino que un acercamiento entre las partes, com exclusión total o parcial de la voluntad del Estado ao respecto, sea lo "más adecuado", ya en abstracto, para así resolver por mediación el conflito penal entre el asesinado y su asesino, entre el genocida y los exterminados, en fin, entre Videla y las Madres de Plaza de Mayo. Y se esto no es posible (p.127 y ss.), es probable que en el modelo propuesto algo essencial esté falando. En cambio, me resulta más tentadora de aceptar, aunque aún no la comparto, la idea de Castex, consecuencia directa e inevitable de su tesis, de vivir el futuro en um mundo libre de fiscales". (Francisco Castex, Sistema Acusatório Material, Buenos Aires, ed.Del Puerto, 2013, p;174

$\mathrm{Na}$ verdade, cuida-se do neoliberalismo globalizante trazido para o "novo" processo penal. Tal visão privatista se vê também no novo código de processo civil, onde as partes podem criar novos procedimentos e prazos diferentes do que nele é regulado. O pior de tudo 
Revista Eletrônica de Direito Processual - REDP.

Rio de Janeiro. Ano 10. Volume 17. Número 2. Julho a Dezembro de 2016

Periódico Semestral da Pós-Graduação Stricto Sensu em Direito Processual da UERJ

Patrono: José Carlos Barbosa Moreira. ISSN 1982-7636. pp. 02-10

www.redp.uerj.br

isto é que alguns companheiros estudiosos do processo penal ainda não perceberam ...

Realmente, o direito é uma superestrutura que vai sendo condicionada pela infraestrutura econômica social liberal.

De há muito, venho me opondo doutrinariamente à "importação" de institutos processuais peculiares ao sistema processual norte-americano, fundado em bases jurídicas e valores sociais diversos da nossa cultura latina.

Por outro lado, temos evoluído em prol do aperfeiçoamento do sistema penal acusatório, mas não devemos chegar ao exagero do que se convencionou chamar de "sistema adversarial”. O processo não é "coisa das partes", mas sim um instrumento público, através do qual o Estado presta a sua jurisdição. O interesse público, cristalizado na legislação cogente, está fora do alcance do poder dispositivo da acusação e da defesa. É o princípio da legalidade, fundante do sistema "civil law", que nos foi legado pela tradição grega e romana.

Assim, não vejo com bons olhos a "ampliação da justiça penal pactuada no processo penal". Já temos a transação penal para as infrações de pequeno potencial ofensivo, nos Juizados Especiais Criminais" e o acordo de cooperação premiada, prevista na legislação que cuida do "crime organizado". O que mais se deseja?

Aliás, tenho escrito muito no sentido de que os tribunais superiores precisam fixar limites interpretativos a este novo instituto, pois constato excessos ilegais em muitas destas “delações premiadas". Não acho possível, por exemplo, que um acordo entre um membro do Ministério Público e um indiciado possa afastar a aplicação das regras do Cod. Penal e da Lei de Execução Penal, prevendo benefícios não previstos na lei de regência ou benefícios por ela não admitidos (penas de reclusão altíssimas em regime domiciliar ...).

Desta forma, não vejo o que ampliar. O membro do Ministério Público (pensemos em um jovem Promotor de Justiça em uma comarca bem distante dos grandes centros) não pode negociar com as regras do direito público, a qualquer pretexto. Não tem ele legitimidade e autorização constitucional para derrogar o direito posto.

Se o processo já não mais é “coisa das partes”, como foi em algum momento da antiguidade, com mais razão, não pertence ao membro do Ministério Público o poder de mudar o que está legislado (conteúdo do processo). O Direito Material, no caso, o Direito Penal, não pode ser objeto de barganha no inquérito ou mesmo na fase processual. 
Revista Eletrônica de Direito Processual - REDP.

Rio de Janeiro. Ano 10. Volume 17. Número 2. Julho a Dezembro de 2016

Periódico Semestral da Pós-Graduação Stricto Sensu em Direito Processual da UERJ

Patrono: José Carlos Barbosa Moreira. ISSN 1982-7636. pp. 02-10

www.redp.uerj.br

Vale dizer, precisamos combater, com todas as nossas forças, esta verdadeira e indesejável privatização do sistema penal. Poder demasiado não fortalecerá o Ministério Público. Ao contrário, vai fragilizá-lo perante a população.

Vejo um certo "deslumbramento" em algumas parcelas do Ministério Público pátrio, mormente do Ministério Público Federal. É preciso não esquecer das realidades totalmente diversas sobre as quais atuam os órgãos do Ministério Público dos Estados. Imaginem as diferenças entre as realidades de países com formação cultural tão distinta. Aliás, em muitos aspectos, temos que reconhecer o grande avanço e desenvolvimento dos Estados Unidos em relação a nós. Entretanto, nas questões sociais pouco precisamos aprender com eles.

Enfim, como professor e estudioso de Direito Processual Penal há 36 anos, estou muito preocupado com o rumo que as coisas estão tomando em nossa sociedade, no que diz respeito ao processo penal. Os interesses corporativos e profissionais, a ignorância ou desinformação de alguns, e o "modismo" de outros, tudo muito por conta do despreparo de nossa grande imprensa, estão "bagunçando" o sistema processual brasileiro, fruto de uma longa e sólida construção teórica, que vem acompanhando o nosso processo civilizatório. Lamentável.

\section{Privatização do processo penal?}

Algumas legislações mais recentes e parte da doutrina "moderna" sustentam a abolição ou "flexibilização" do princípio da obrigatoriedade do exercício da ação penal pública. Entretanto, tais legislações e estes autores aumentam a hipótese de cabimento da ação penal privada subsidiária da pública. Caberia tal esdrúxula ação privada não só na inércia do Ministério Público, mas também quando ele, prestigiando o princípio da oportunidade, deixar de oferecer a sua denúncia ao órgão jurisdicional competente.

Vale dizer, substituem um órgão do Estado, que tem as mesmas garantias da magistratura, pela acusação do ofendido (vítima), que se move por desejos pessoais e privados, embora compreensíveis. Por vezes, a vítima é motivada até por sentimentos escusos ou não muito próprios para instauração de um processo penal democrático.

Sob certo aspecto, estaremos retornando ao sistema processual vigente antes do século XVII. Trata-se de mais um passo para a privatização do nosso processo penal. Lamentável é que parcela do próprio Ministério Público não está percebendo isto, seduzido pelo indesejável sistema adversarial norte-americano. 
Revista Eletrônica de Direito Processual - REDP.

Rio de Janeiro. Ano 10. Volume 17. Número 2. Julho a Dezembro de 2016

Periódico Semestral da Pós-Graduação Stricto Sensu em Direito Processual da UERJ

Patrono: José Carlos Barbosa Moreira. ISSN 1982-7636. pp. 02-10

www.redp.uerj.br

Contundente é a crítica a este sistema por parte do catedrático da Universidade de

Valencia, professor Juan Montero Arouca, um dois maiores processualistas da Espanha. Tal extensa crítica está em seu importante livro intitulado "Proceso Penal y Liberdad, Ensayo polémico sobre el nuevo processo penal”, Madrid, Ed.Aranzadi, 2008, p.76/80; mais especialmente no capítulo que denominou "El absurdo intento de monopolizar la idea de processo acusatório o, si se prefere, del sistema que se llama adversarial”.

Somos a favor de um processo penal acusatório público, onde prevaleça o interesse da sociedade, seja através de uma acusação responsável, seja através uma defesa substancial e eficaz. As partes não podem transigir com as regras cogentes do Direito Penal e não devem poder renunciar aos seus deveres processuais.

\section{Será que não perceberam?}

Abandonar o princípio da obrigatoriedade do exercício da ação penal pública é dar ao membro do Ministério Público o poder discricionário de denunciar ou não este ou aquele crime, este ou aquele indiciado. É colocar o Promotor ou Procurador da República como titular exclusivo de se aplicar ou não a lei penal, que é de natureza pública. É dar-lhe o poder discricionário de discernir se está ou não presente o interesse público.

O princípio da oportunidade não é nada democrático, por isso a Constituição da Itália expressamente obriga o exercício da ação penal, lógico que presentes as condições que a lei exige para tal. Na época do fascismo, o Ministério Público da Itália acusava quem fosse do interesse do governo autoritário.

Note-se que a realidade do nosso país é bem diversa da de outros países. Não podemos pensar apenas nos grandes centros mais desenvolvidos. Temos de perceber que, no interior do país, as coisas são bem diversas. Imaginem se o fazendeiro de longínqua área rural, por onde tem que passar o Promotor de Justiça, em seu carro, para chegar ao fórum, souber que este Promotor pode ou não denunciar o capataz de sua fazenda ... O princípio da obrigatoriedade funciona, nesta medida, também como uma "defesa" da atuação do membro do Ministério Público.

Ademais, qual o critério a ser adotado para existir ou não uma acusação facultativa? Poder demasiado não vai fortalecer a Instituição, mas vai fragilizá-la perante a opinião pública. 
Revista Eletrônica de Direito Processual - REDP.

Rio de Janeiro. Ano 10. Volume 17. Número 2. Julho a Dezembro de 2016

Periódico Semestral da Pós-Graduação Stricto Sensu em Direito Processual da UERJ

Patrono: José Carlos Barbosa Moreira. ISSN 1982-7636. pp. 02-10

www.redp.uerj.br

O Direito Penal é que tem de resolver a questão, descriminalizando inúmeras infrações penais sem relevância social (princípio da intervenção mínima do Direito Penal). Por outro lado, o princípio da insignificância já legitima o não oferecimento da denúncia, tendo em vista a atipicidade da conduta, por ausência de bem jurídico a ser tutelado.

Outra medida aceitável seria ampliar as hipótese de ação penal pública condicionada à representação do ofendido, mormente para os crimes contra o patrimônio e outras infrações, desde que seja disponível o bem jurídico tutelado pela norma penal incriminadora.

$\mathrm{O}$ argumento de que a polícia e até alguns órgãos do Ministério Público já não obedecem, na prática, ao nosso sistema processual, não tem qualquer respaldo lógico. Seria o mesmo que revogar o artigo 121 do Cod. Penal, porque os homicídios continuam sendo praticados. Aliás, se com a regra da obrigatoriedade, já se criticam tais omissões, imaginem sem ela ...

Vamos parar de modismos, de imitar o sistema norte-americano, onde tudo é diferente, seja na cultura, seja na organização do Ministério Público, seja na estrutura do Poder Judiciário. Noventa por cento dos casos não são levados a juízo e os questionáveis e suspeitos acordos do Ministério Público e investigados são feitos tendo em vista a "prova" inquisitória, colhida pela polícia. O chamado sistema adversarial somente se faz sentir para muitos poucos casos. Lá também existe a "lei do menor esforço" ... Neste sentido, veja-se o que nos informa o grande professor, meu mestre de sempre, José Carlos Barbosa Moreira, sobre o funcionamento do sistema penal norte-americano, nota de rodapé n.6: "em obra muito recente, o dado impressiona: apenas cerca de $2 \%$ de todos os processos penais se resolveriam por meio do "trial" (Samaha, Criminal Procedure, 4a.edição, Belmont, 1998, p.37)." Temas de Direito Processual, Oitava Série, S.Paulo, Saraiva, 2004, p.8).

\section{Para encerrar, com a palavra o nosso maior processualista.}

Uma visão publicista do sistema processual: Paralelamente a outras leituras, decidi ler (ou reler) os principais trabalhos que o professor José Carlos Barbosa Moreira - para mim, o maior processualista brasileiro de todos os tempos - reuniu nos nove volumes publicados sob o título "Temas de Direito Processual". 
Revista Eletrônica de Direito Processual - REDP.

Rio de Janeiro. Ano 10. Volume 17. Número 2. Julho a Dezembro de 2016

Periódico Semestral da Pós-Graduação Stricto Sensu em Direito Processual da UERJ

Patrono: José Carlos Barbosa Moreira. ISSN 1982-7636. pp. 02-10

www.redp.uerj.br

Comecei a leitura pelos estudos mais recentes do mestre. Evidentemente, pelo nosso contato na UERJ e pela leitura de seus livros, já conhecia a sua predileção pela sistemática publicista do "processo" e, por ela, fui fortemente influenciado. Talvez por isso, tenha escrito a minha dissertação de mestrado, no longínquo ano de 1981, com o título "Da Publicização do Processo Civil", depois publicada pela antiga ed. Liber Iuris.

Hoje, o meu embate é contra a "privatização do processo penal”, que se busca através da adoção de um sistema acusatório puro ou radical, próximo do sistema adversarial, tão a gosto dos Estados Unidos e da Inglaterra (paraísos dos liberalismos políticos e econômicos), países que privilegiam o individualismo e o "darwinismo social". Tudo isso, importado para os países mais pobres, determina uma total injustiça social, pois o "deus mercado" não distribui riqueza, mas, ao contrário, concentra aquilo que é produzido pela mão do trabalhador em papéis que fazem a fortuna de alguns poucos.

Embora com os olhos voltados mais para o processo civil, o prof. José Carlos Barbosa Moreira, com a clareza e concisão que sempre o caracterizaram, disse o que eu gostaria de ter dito, por isso que transcrevo abaixo. Não tenho dúvida de que vale também para o processo penal:

“Já no que tange à repartição de atribuições entre o órgão judicial e os litigantes na atividade de instrução, nem ao mais superficial observador escapará a dimensão política - ou, se preferir, ideológica - da problemática. Cercear a participação do juiz e confiar às partes ( ou melhor: aos advogados) a condução do mecanismo probatório é opção que transcende com absoluta nitidez o plano da técnica: põe de manifesto a adesão a um ideário liberal, tomada a palavra no sentido individualístico - no sentido em que era costume usá-la para designar o pensamento dominante na maior parte do século XIX e atualmente é lícito usá-la para designar o pensamento dominante no início do século XXI. Esse pensamento parte de uma premissa: a melhor solução para as questões da convivência humana é a que resulta do livre embate entre os interessados, com a presença do Estado reduzida à de mero 
Revista Eletrônica de Direito Processual - REDP.

Rio de Janeiro. Ano 10. Volume 17. Número 2. Julho a Dezembro de 2016

Periódico Semestral da Pós-Graduação Stricto Sensu em Direito Processual da UERJ

Patrono: José Carlos Barbosa Moreira. ISSN 1982-7636. pp. 02-10

www.redp.uerj.br

físcal da observância de certas "regras do Jogo". Projetada na

tela da economia, semelhante idéia leva à glorificação do

mercado como supremo regulador da vida social. Projetada na

tela da Justiça, fornece apoio a uma concepção de processo

modelada à imagem de duelo ou, se se quiser expressão menos

belicosa, de competição desportiva. (Temas de Direito

Processual, 9 série, 2007. Saraiva. P. 65-66)".

Evidentemente que é legítima a opção pelo sistema processual liberal-individualista, onde o Estado aparece como um mero árbitro do duelo entre dois jogadores e adversários. Entretanto, parece que muitos que defendem tal sistema não perceberam ainda que isto está ligado a uma escolha ideológica. A minha, sendo pela justiça social, não pode prescindir da atuação efetiva do Estado, que se deseja seja cada vez mais democratizado e atento ao interesse da população mais pobre. 